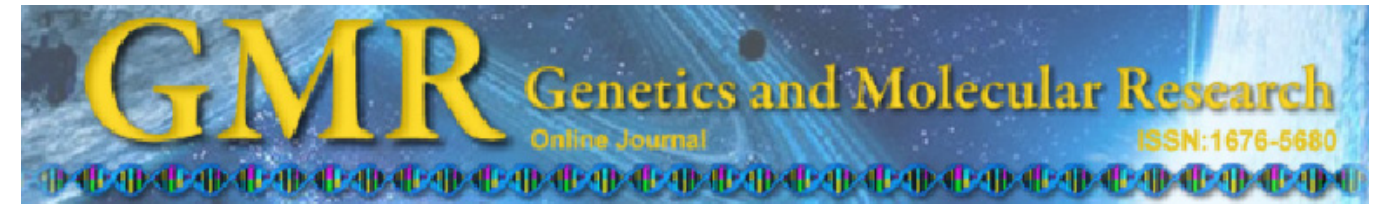

\title{
Genetic polymorphism of the glutathione-S- transferase P1 gene (GSTP1) and susceptibility to prostate cancer in the Kashmiri population
}

\author{
Q. Qadri' ${ }^{1}$, A.S. Sameer ${ }^{1,2}$, Z.A. Shah ${ }^{1}$, A. Hamid ${ }^{3}$, S. Alam ${ }^{1}$, S. Manzoor ${ }^{1}$ \\ and M.A. Siddiqi ${ }^{1}$ \\ ${ }^{1}$ Department of Immunology and Molecular Medicine, \\ Sher-I-Kashmir Institute of Medical Sciences, Soura, Srinagar, Kashmir, India \\ ${ }^{2}$ Department of Clinical Biochemistry, \\ Sher-I-Kashmir Institute of Medical Sciences, Soura, Srinagar, Kashmir, India \\ ${ }^{3}$ Department of Urology, Sher-I-Kashmir Institute of Medical Sciences, Soura, \\ Srinagar, Kashmir, India \\ Corresponding author: M.A. Siddiqi \\ E-mail: mousvi786@gmail.com / vc.tmuk@gmail.com
}

Genet. Mol. Res. 10 (4): 3038-3045 (2011)

Received March 15, 2011

Accepted August 10, 2011

Published December 6, 2011

DOI http://dx.doi.org/10.4238/2011.December.6.4

\begin{abstract}
Glutathione-S-transferase P1 (GSTP1) is a critical enzyme of the phase II detoxification pathway. One of the common functional polymorphisms of GSTP1 is $\mathrm{A} \rightarrow \mathrm{G}$ at nucleotide 313 , which results in an amino acid substitution (Ile105Val) at the substrate binding site of GSTP1 and reduces catalytic activity of GSTP1. To investigate the GSTP1 Ile105Val genotype frequency in prostate cancer cases in the Kashmiri population, we designed a case-control study, in which 50 prostate cancer cases and 45 benign prostate hyperplasia cases were studied for GSTP1 Ile105 Val polymorphism, compared to 80 controls taken from the general population, employing the PCR-RFLP technique. We found the frequency of the three different genotypes of GSTP1 Ile105Val in our ethnic Kashmir population, i.e., Ile/Ile, Ile/ $\mathrm{Val}$ and $\mathrm{Val} / \mathrm{Val}$, to be $52.4,33.3$ and $14.3 \%$ among prostate cancer cases, $48.5,37.5$ and $14 \%$ among benign prostate hyperplasia cases and
\end{abstract}


$73.8,21.3$ and $5 \%$ in the control population, respectively. There was a significant association between the GSTP1 Ile/Val genotype and the advanced age group among the cases. We conclude that GSTP1 Ile/Val polymorphism is involved in the risk of prostate cancer development in our population.

Key words: Prostate cancer; GSTP1; Polymorphism; RFLP; Kashmir; Restriction digestion

\section{INTRODUCTION}

Prostate cancer is the most common cancer diagnosed in men today, with a higher rate of incidence being found in North America and Europe. Rates of detection of prostate cancer vary widely across the world, with South and East Asia detecting less frequently than in Europe, and the United States. Age, ethnicity, family history, and diet contribute significantly to prostate cancer risk (Bostwick et al., 2004).

The development of prostate cancer is governed by a variety of environmental and genetic factors. Previous studies suggest that oxidative stress and reactive oxygen species (ROS) are important in the progression of prostate carcinogenesis (Fleshner and Klotz, 1998; Kelada et al., 2000; Sikka, 2003; Ntais et al., 2005; Hsing and Chokkalingam, 2006; Mo et al., 2009). Failure to remove these molecules may cause damage to biomolecules, ultimately leading to cellular dysfunction or transformation. As such, the role of the various antioxidants has been extensively studied in relation to the development of carcinogenesis (Fleshner and Klotz, 1998; Abate-Shen and Shen, 2000; Miyake et al., 2004; Waris and Ahsan, 2006; Choi et al., 2007).

One such gene involved in the detoxification of carcinogens and antioxidant activity is the glutathione-S-transferase P1 (GSTP1) gene. This gene has been observed to be markedly downregulated in prostate carcinogenesis. The GSTP1 gene, located on chromosome 11q13, is involved in the detoxification of electrophillic and heterocyclic amine carcinogens by conjugation (Zimniak et al., 1994; Henderson et al., 1998) and protection of DNA from oxidative damage (Ryberg et al., 1997). GSTP1 has a polymorphic site at codon 105 (exon 5), where an adenosine-to-guanosine (A-G) transition causes an Ile-to-Val substitution (I105V). The substitution of the less bulkier and more hydrophobic valine results in substrate-dependent alterations of GSTP1 catalytic activity. The presence of this valine residue in close proximity to the hydrophobic binding site for electrophilic substrates has been associated with decreased enzyme activity and a propensity to develop different neoplasms (Garcia-Sae et al., 1994).

In this study, we investigated the association between the GSTP1 Ile105 Val polymorphism and the risk for developing prostate cancer, by determining the primary genotypic effect on prostate cancer susceptibility.

\section{MATERIAL AND METHODS}

\section{Patients and tumor tissue procurement}

A cohort of 95 randomly selected male patients admitted to the Department of Urol- 
ogy, Sher-i-Kashmir Institute of Medical Sciences, was included in the study. The patients underwent histopathological diagnosis of prostate cancer at the Department of Histopathology of our institution. Fifty prostate tumor samples and 45 benign hyperplasia (BHP) samples were collected. Samples from 80 healthy males over 50 years of age served as controls. The study was approved by the Ethics Committee of the Sher-i-Kashmir Institute of Medical Sciences. Only men with histologically confirmed prostate cancer were included in the study; all had high Gleason scores (6-9), which were detected at an advanced stage. The ethnic origin for cases and controls was similar. The inclusion criteria for the controls were the absence of any previous history of cancer or pre-cancerous lesions, and serological (PSA $<4 \mathrm{ng} / \mathrm{mL}$ ), physical (digital rectal examination) and radiological examinations were performed to exclude the possibility of malignancy (Table 1).

\begin{tabular}{|c|c|c|c|c|c|}
\hline Variable & Controls $(\mathrm{N}=80)$ & Cancer cases $(\mathrm{N}=50)$ & BHP cases $(\mathrm{N}=45)$ & $\begin{array}{c}\text { P value } \\
\text { (controls vs cancer cases) }\end{array}$ & $\begin{array}{c}\text { P value } \\
\text { (controls } v s \mathrm{BHP} \text { ) }\end{array}$ \\
\hline \multicolumn{6}{|l|}{ Age group } \\
\hline$\leq 50$ years & $28(35 \%)$ & $47(94 \%)$ & $42(93.30 \%)$ & 6.38 & 1.0 \\
\hline$>50$ years & $52(65 \%)$ & $3(6 \%)$ & $3(6.60 \%)$ & & \\
\hline \multicolumn{6}{|l|}{ Dwelling } \\
\hline Rural & $52(65 \%)$ & $38(76 \%)$ & $31(68.8 \%)$ & 0.24 & 0.69 \\
\hline Urban & $28(35 \%)$ & $12(24 \%)$ & $14(31.2 \%)$ & & \\
\hline \multicolumn{6}{|c|}{ Smoking status } \\
\hline No & $37(46.2 \%)$ & $11(22 \%)$ & $18(40.0 \%)$ & 0.51 & 0.57 \\
\hline Yes & $43(53.8 \%)$ & $39(78 \%)$ & $27(60.0 \%)$ & & \\
\hline
\end{tabular}

$\mathrm{BHP}=$ benign hyperplasia.

\section{DNA isolation}

Blood was collected from all individuals, and genomic DNA was extracted from fresh peripheral leukocytes by ammonium acetate precipitation method.

\section{GSTP1 genotype analysis}

The exon 5 polymorphic site in GSTP1 locus (Ile105Val) was detected by restriction fragment length polymorphism (RFLP) of PCR-amplified fragments.

The primers used were: P105F: 5'-ACC CCA GGG CTC TAT GGG AA-3' and P105R: 5'-TGA GGG CAC AAG AAG CCC CT-3' (Table 2). PCR was carried out in a 30- $\mu \mathrm{L}$ volume containing about $50 \mathrm{ng}$ genomic DNA template, $200 \mu \mathrm{M}$ of each dNTP, $200 \mathrm{ng}$ of each primer, $1.5 \mathrm{mM} \mathrm{MgCl}_{2}, 1 \mathrm{X}$ PCR buffer (50 $\mathrm{mM} \mathrm{KCl}, 10 \mathrm{mM}$ Tris- $\left.\mathrm{HCl}, \mathrm{pH} 8.3\right)$, and $1 \mathrm{U}$ Taq DNA polymerase (Promega, Southampton, UK). After an initial denaturation step of $10 \mathrm{~min}$ at $95^{\circ} \mathrm{C}$, the samples were processed through 30 temperature cycles of $30 \mathrm{~s}$ at $94^{\circ} \mathrm{C}, 30 \mathrm{~s}$ at $55^{\circ} \mathrm{C}$, and $30 \mathrm{~s}$ at $72^{\circ} \mathrm{C}$. A final extension step of $72^{\circ} \mathrm{C}$ for $10 \mathrm{~min}$ was performed. The 176-bp PCR products $(20 \mu \mathrm{L})$ were digested for $2 \mathrm{~h}$ at $37^{\circ} \mathrm{C}$ with $2 \mathrm{U}$ Alw $26 \mathrm{I}$ (Fermentas Inc., Vilnius, Lithuania). The detection of the different alleles was carried out by horizontal $4 \%$ agarose gel electrophoresis with ethidium bromide, along with a 100-bp DNA ladder (Figure 1). 
Table 2. Primers for GSTP1 codon 105 polymorphism.

\begin{tabular}{llc}
\hline Target codon & Sequence & Amplicon $(\mathrm{bp})$ \\
\hline 105 & P105F: 5'-ACC CCA GGG CTC TAT GGG AA-3' & 176 \\
& P105R: 5'-TGA GGG CAC AAG AAG CCC CT-3' & \\
\hline
\end{tabular}

$\mathrm{T}_{\mathrm{m}}=$ melting temperature.

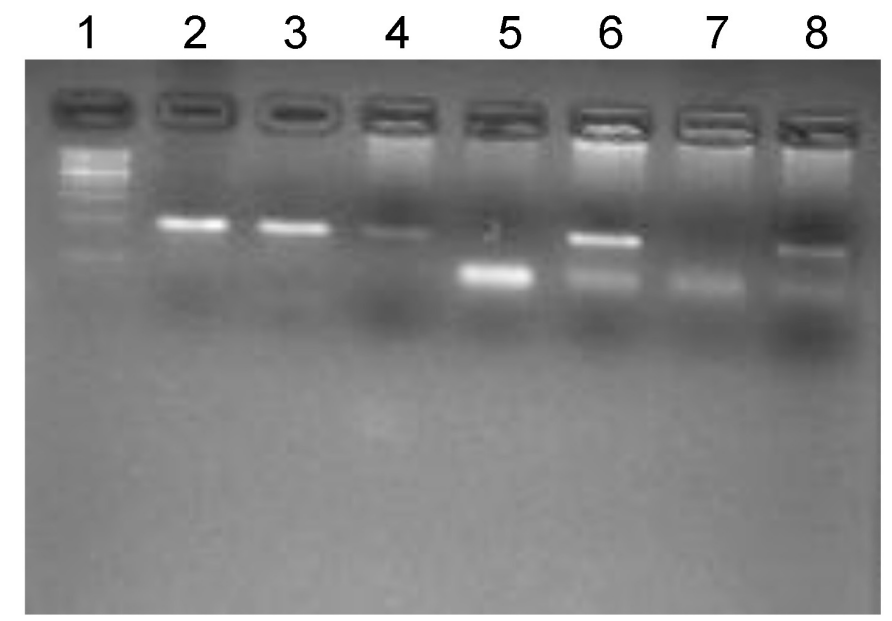

Figure 1. PCR-restriction fragment length polymorphism analysis of the GSTP1 Ile105Val polymorphism. The consensus sequence corresponding to the GSTP1 Iso allele was not cut, whereas the Val sequence corresponding to the GSTP1 Val allele was cleaved to yield two fragments (91 and $85 \mathrm{bp})$. Lanes 2-4 = Wild-type homozygote (GSTP1 Ile/Ile); lane 6 and $8=$ heterozygote (GSTP1Iso/Val); lane 5 and $7=$ homozygous mutant (GSTP1Val/ Val) cases, respectively; lane $1=100-\mathrm{bp}$ DNA ladder.

\section{Statistical analysis}

Observed frequencies of genotypes in PCA were compared to BHP and controls using chi-square or Fisher exact tests when expected frequencies were small. The chi-square test was used to determine whether genotype distributions were in Hardy-Weinberg equilibrium. Statistical significance was set at $\mathrm{P}<0.05$. Statistical analyses were performed using the PASW version 18 software.

\section{RESULTS}

A total of 50 prostate cancer patients, 45 BHP patients and 80 control subjects were included in this study. Mean age in the patient and control groups was 50 years. No significant age-related differences were observed between the groups $(\mathrm{P}>0.05)$. Furthermore, of the 50 confirmed cases of prostate cancer, 38 were rural and 12 were urban, 39 were smokers and 11 nonsmokers, and 39 had occupational pesticide exposure whereas 11 did not. Of the 45 cases of BHP, 31 were rural and 14 were urban, while 27 were smokers and 18 were nonsmokers.

In our study, we found a variable difference in the GSTP1 Ile105 Val polymorphism between prostate cancer cases and the matched controls. The frequency of the GSTP1 Val allele was higher in patients with prostate cancer and BHP compared with healthy controls 
(Tables 3 and 4). The frequency of the Ile/Val genotype was 33.33\% and that of Val/Val was $14.29 \%$ in prostate cancer cases, and 37.5 and $14 \%$ in BHP cases as compared to healthy controls, where it was 21.25 and $5 \%$, respectively.

\begin{tabular}{|c|c|c|c|c|c|c|}
\hline & & Cases $(\mathrm{N}=50)$ & BHP cases $(\mathrm{N}=45)$ & Controls $(\mathrm{N}=80)$ & $\begin{array}{c}\text { P value; } \chi^{2} \\
\text { (controls } v s \text { cancer cases) }\end{array}$ & $\begin{array}{c}\text { P value; } \chi^{2} \\
\text { (controls vs } \mathrm{BHP} \text { ) }\end{array}$ \\
\hline \multirow{3}{*}{$\begin{array}{l}\text { Ile } 105 \mathrm{Val} \\
\mathrm{A} \rightarrow \mathrm{G}\end{array}$} & Ile/Ile & $26(52.38 \%)$ & $22(48.5 \%)$ & $59(73.75 \%)$ & $0.02 ; 7.08$ & $0.01 ; 8.14$ \\
\hline & $\mathrm{Ile} / \mathrm{Val}$ & $17(33.33 \%)$ & $17(37.5 \%)$ & $17(21.25 \%)$ & & \\
\hline & $\mathrm{Val} / \mathrm{Val}$ & $7(14.29 \%)$ & $6(14 \%)$ & $4(5 \%)$ & & \\
\hline
\end{tabular}

$\mathrm{BHP}=$ benign hyperplasia.

\begin{tabular}{|c|c|c|c|c|c|}
\hline Variable & $\mathrm{N}=50$ & Ile/Ile [26 (52.38\%)] & Ile/Val [17 (33.33\%)] & $\mathrm{Val} / \mathrm{Val}[7(14.28 \%)]$ & $P$ value \\
\hline \multicolumn{6}{|l|}{ Age group } \\
\hline$\leq 50$ years & $44(88 \%)$ & 25 & 14 & 5 & \multirow[t]{2}{*}{0.04} \\
\hline$>50$ years & $6(12 \%)$ & 1 & 3 & 2 & \\
\hline \multicolumn{6}{|l|}{ Dwelling } \\
\hline Rural & $38(76 \%)$ & 23 & 10 & 5 & \multirow[t]{2}{*}{0.05} \\
\hline Urban & $12(24 \%)$ & 3 & 7 & 2 & \\
\hline \multicolumn{6}{|l|}{ Smoking status } \\
\hline Ever & $32(64 \%)$ & 24 & 3 & 5 & \multirow[t]{2}{*}{8.86} \\
\hline Never & $18(36 \%)$ & 2 & 14 & 2 & \\
\hline \multicolumn{6}{|l|}{ PSA level } \\
\hline Low $(4-8$ ng/dL) & $12(24 \%)$ & 9 & 2 & 1 & \multirow[t]{2}{*}{0.20} \\
\hline $\operatorname{High}(8-12 \mathrm{ng} / \mathrm{dL})$ & $38(76 \%)$ & 17 & 15 & 6 & \\
\hline
\end{tabular}

In this study, we found that the allele and genotype frequencies of GSTP1 Ile 105Val in cancer cases and controls differed significantly $(P=0.02)$. Similarly, we found that the allele and genotype frequencies of GSTP1 Ile105Val in BHP cases and controls also differed significantly $(\mathrm{P}=0.01)$ (Table 3$)$.

The correlation of GSTP1 Ile105Val polymorphic status with the clinical characteristics was carefully analyzed. It was found that the Val/Val variant status increased the risk of prostate cancer in the higher age group. It was also found that the Val/Val variant status increased the risk of BHP in patients with rural dwelling (Tables 4 and 5).

Table 5. Association between the GSTP1 codon 105 genotype and clinicopathological characteristics of benign hyperplasia (BHP) cases.

\begin{tabular}{|c|c|c|c|c|c|}
\hline Variable & $\mathrm{N}=45$ & Ile/Ile [22 (48.5\%)] & Ile/Val [17 (37.5\%)] & $\mathrm{Val} / \mathrm{Val}[6(14 \%)]$ & $\chi^{2}$; P value \\
\hline \multicolumn{6}{|l|}{ Age group } \\
\hline$\leq 50$ years & $41(92 \%)$ & 20 & 16 & 5 & 0.61 \\
\hline$>50$ years & $4(8 \%)$ & 2 & 1 & 1 & \\
\hline \multicolumn{6}{|l|}{ Dwelling } \\
\hline Rural & $31(68 \%)$ & 20 & 8 & 3 & 0.003 \\
\hline Urban & $14(32 \%)$ & 2 & 9 & 3 & \\
\hline \multicolumn{6}{|l|}{ Smoking status } \\
\hline Ever & $31(69 \%)$ & 15 & 11 & 5 & 0.82 \\
\hline Never & $14(31 \%)$ & 7 & 6 & 1 & \\
\hline \multicolumn{6}{|l|}{ PSA level } \\
\hline Low (4-8 ng/dL) & $14(31 \%)$ & 6 & 6 & 2 & 0.90 \\
\hline High (8-12 ng/dL) & $31(69 \%)$ & 16 & 11 & 4 & \\
\hline
\end{tabular}




\section{DISCUSSION}

In this study, we investigated the association of the GSTP1 Ile105Val polymorphism with predisposition to prostate cancer in the Kashmiri population.

PCA tissues appear to contain higher amounts of ROS and oxidative DNA damage (Fleshner and Klotz, 1998; Abate-Shen and Shen, 2000; Miyake et al., 2004; Waris and Ahsan, 2006; Choi et al., 2007). Variations within the genes responsible for antioxidant activity can cause a loss of or reduction in enzymatic activity. Such decreased antioxidant activity has been associated with increased risk of prostate cancer as well as several other cancers (e.g., colon, breast, and lung) (Hayes and Strange, 2000; Sreeja et al., 2008; McCarty et al., 2009; Mir et al., 2009). One such enzyme is GSTP1. Any alteration in GSTP1 enzyme activity results in a decreased or poorer elimination of carcinogens and ROS, which could lead to tumor development (Rebbeck, 1997).

We sought to confirm the finding by Harries et al. (1997) who reported that the Ile/Ile genotype is associated with a decreased risk of prostate cancer in a study of 36 prostate cancer patients. In our current study, we investigated 50 prostate cancer cases, 45 BHPs and 80 normal controls. We found the GSTP1 (Val/Val) genotype to be significantly associated with a greater risk of benign hyperplasia as well as cancer of the prostate. We found the frequency of the Ile/ Val genotype to be $33.33 \%$ and that of Val/Val to be $14.29 \%$ in prostate cancer cases, 37.5 and $14 \%$ in BHP cases and 21.25 and $5 \%$ in healthy controls, respectively. These findings were consistent with the already reported studies, where the Ile/Val and Val/Val genotypes were associated with a significant increase in the risk of prostate cancer in Japanese (Nakazato et al., 2003), Italian (Antognelli et al., 2005) and North Indian populations (Srivastava et al., 2005).

Another study conducted in the UK (Kote-Jarai et al., 2001) also reported that patients with the GSTP1 Ile105Val polymorphism were predisposed to early onset prostate cancer. This was in sharp contrast to a study from south India (Vijayalakshmi et al., 2005), which has reported a significant decrease in the Val allele (Ile/Val and Val/Val) among cases compared to controls, suggesting that the Val allele is associated with a decreased risk for prostate cancer. However, the three genotypes of GSTP1 in BHP samples from our population had the similar frequencies for Ile/Val and Val/Val as reported by Srivastava et al. (2005) and Konwar et al. (2010). In addition, Swedish, Danish and German case-control studies that evaluated the GSTP1 genotype failed to report an association between GSTP1 and prostate cancer risk (Autrup et al., 1999; Wadelius et al., 1999; Steinhoff et al., 2000).

Also, in separate studies conducted in the United States in Caucasian men (Shepard et al., 2000), Portuguese men (Jeronimo et al., 2002) and on sporadic and familial prostate cancer in American families (Debes et al., 2004), no association was found between the GSTP1 Ile105Val polymorphism and prostate cancer risk. Thus, these studies indicate that the predisposition of the GSTP1 Ile105Val polymorphism to prostate cancer differs widely among different populations, suggesting that ethnic differences and environmental factors contribute to prostate cancer susceptibility.

Adler and co-workers (1999) have reported that GSTP1 can act to alter intracellular signaling through an interaction with Jun N-terminal kinase (JNK), besides catalyzing the conjugation of nucleophiles. Decreased GSTP1 expression may therefore alter intracellular signaling. This change in signaling would explain the role of GSTP1 in prostate carcinogenesis.

In a nutshell, this study revealed a significant correlation between the $\mathrm{Val} / \mathrm{Val}$ variant 
genotype of GSTP1 and various clinicopathologic variables in this ethnic Kashmiri population, especially in the older age group. However, these correlations need to be authenticated in a large-sample study in the future.

\section{CONCLUSION}

Hence, in this study, carried out for the first time in the Kashmir Valley, we observed a significant correlation between the $\mathrm{Val} / \mathrm{Val}$ GSTP1 variant and predisposition to prostate cancer in the Kashmiri population.

\section{ACKNOWLEDGMENTS}

Research supported by the Indian Council of Medical Research (ICMR), New Delhi (\#5/13/40/2007-NCD-III). The fellowships of Q. Qadri and S. Manzoor were supported by ICMR. We are grateful to the Head and Technical Staff of the operation theater of the Department of Urology who helped us in the sample procurement. We also thank the anonymous pathologists of Department of Pathology for the histopathological assessment of the tumor tissues.

\section{REFERENCES}

Abate-Shen C and Shen MM (2000). Molecular genetics of prostate cancer. Genes Dev. 14: 2410-2434.

Adler V, Yin Z, Fuchs SY, Benezra M, et al. (1999). Regulation of JNK signaling by GSTp. EMBO J. 18: 1321-1334

Antognelli C, Mearini L, Talesa VN, Giannantoni A, et al. (2005). Association of CYP17, GSTP1, and PON1 polymorphisms with the risk of prostate cancer. Prostate 63: 240-251.

Autrup JL, Thomassen LH, Olsen JH, Wolf H, et al. (1999). Glutathione S-transferases as risk factors in prostate cancer. Eur. J. Cancer Prev. 8: 525-532.

Bostwick DG, Burke HB, Djakiew D, Euling S, et al. (2004). Human prostate cancer risk factors. Cancer 101: 2371-2490.

Choi JY, Neuhouser ML, Barnett M, Hudson M, et al. (2007). Polymorphisms in oxidative stress-related genes are not associated with prostate cancer risk in heavy smokers. Cancer Epidemiol. Biomarkers Prev. 16: 1115-1120.

Debes JD, Yokomizo A, McDonnell SK, Hebbring SJ, et al. (2004). Gluthatione-S-transferase P1 polymorphism I105V in familial and sporadic prostate cancer. Cancer Genet. Cytogenet. 155: 82-86.

Fleshner NE and Klotz LH (1998). Diet, androgens, oxidative stress and prostate cancer susceptibility. Cancer Metastasis Rev. 17: 325-330.

Garcia-Saez I, Parraga A, Phillips MF, Mantle TJ, et al. (1994). Molecular structure at $1.8 \AA$ of mouse liver class pi glutathione S-transferase complexed with S-(p-nitrobenzyl)glutathione and other inhibitors. J. Mol. Biol. 237: 298314.

Harries LW, Stubbins MJ, Forman D, Howard GC, et al. (1997). Identification of genetic polymorphisms at the glutathione S-transferase Pi locus and association with susceptibility to bladder, testicular and prostate cancer. Carcinogenesis 18: 641-644.

Hayes JD and Strange RC (2000). Glutathione S-transferase polymorphisms and their biological consequences. Pharmacology 61: 154-166.

Henderson CJ, McLaren AW, Moffat GJ, Bacon EJ, et al. (1998). $\pi$-class glutathione S-transferase: regulation and function. Chem. Biol. Interact. 111-112: 69-82.

Hsing AW and Chokkalingam AP (2006). Prostate cancer epidemiology. Front. Biosci. 11: 1388-1413.

Jeronimo C, Varzim G, Henrique R, Oliveira J, et al. (2002). I105V polymorphism and promoter methylation of the GSTP1 gene in prostate adenocarcinoma. Cancer Epidemiol. Biomarkers Prev. 11: 445-450.

Kelada SN, Kardia SL, Walker AH, Wein AJ, et al. (2000). The glutathione S-transferase-mu and -theta genotypes in the etiology of prostate cancer: genotype-environment interactions with smoking. Cancer Epidemiol. Biomarkers Prev. 9: 1329-1334.

Konwar R, Manchanda PK, Chaudhary P, Nayak VL, et al. (2010). Glutathione S-transferase (GST) gene variants and risk 
of benign prostatic hyperplasia: a report in a North Indian population. Asian Pac. J. Cancer Prev. 11: 1067-1072.

Kote-Jarai Z, Easton D, Edwards SM, Jefferies S, et al. (2001). Relationship between glutathione S-transferase M1, P1 and T1 polymorphisms and early onset prostate cancer. Pharmacogenetics 11: 325-330.

McCarty KM, Santella RM, Steck SE, Cleveland RJ, et al. (2009). PAH-DNA adducts, cigarette smoking, GST polymorphisms, and breast cancer risk. Environ. Health Perspect. 117: 552-558.

Mir O, Alexandre J, Tran A, Durand JP, et al. (2009). Relationship between GSTP1 Ile(105)Val polymorphism and docetaxel-induced peripheral neuropathy: clinical evidence of a role of oxidative stress in taxane toxicity. Ann. Oncol. 20: 736-740.

Miyake H, Hara I, Kamidono S and Eto H (2004). Oxidative DNA damage in patients with prostate cancer and its response to treatment. J. Urol. 171: 1533-1536.

Mo Z, Gao Y, Cao Y, Gao F, et al. (2009). An updating meta-analysis of the GSTM1, GSTT1, and GSTP1 polymorphisms and prostate cancer: a HuGE review. Prostate 69: 662-688.

Nakazato H, Suzuki K, Matsui H, Koike H, et al. (2003). Association of genetic polymorphisms of glutathione-S-transferase genes (GSTM1, GSTT1 and GSTP1) with familial prostate cancer risk in a Japanese population. Anticancer Res. 23: 2897-2902.

Ntais C, Polycarpou A and Ioannidis JP (2005). Association of GSTM1, GSTT1, and GSTP1 gene polymorphisms with the risk of prostate cancer: a meta-analysis. Cancer Epidemiol. Biomarkers Prev. 14: 176-181.

Rebbeck TR (1997). Molecular epidemiology of the human glutathione S-transferase genotypes GSTM1 and GSTT1 in cancer susceptibility. Cancer Epidemiol. Biomarkers Prev. 6: 733-743.

Ryberg D, Skaug V, Hewer A, Phillips DH, et al. (1997). Genotypes of glutathione transferase M1 and P1 and their significance for lung DNA adduct levels and cancer risk. Carcinogenesis 18: 1285-1289.

Shepard TF, Platz EA, Kantoff PW, Nelson WG, et al. (2000). No association between the I105V polymorphism of the glutathione S-transferase P1 gene (GSTP1) and prostate cancer risk: a prospective study. Cancer Epidemiol. Biomarkers Prev. 9: 1267-1268.

Sikka SC (2003). Role of oxidative stress response elements and antioxidants in prostate cancer pathobiology and chemoprevention - a mechanistic approach. Curr. Med. Chem. 10: 2679-2692.

Sreeja L, Syamala V, Hariharan S, Syamala VS, et al. (2008). Glutathione S-transferase M1, T1 and P1 polymorphisms: susceptibility and outcome in lung cancer patients. J. Exp. Ther. Oncol. 7: 73-85.

Srivastava DS, Mandhani A, Mittal B and Mittal RD (2005). Genetic polymorphism of glutathione S-transferase genes (GSTM1, GSTT1 and GSTP1) and susceptibility to prostate cancer in Northern India. BJU Int. 95: 170-173.

Steinhoff C, Franke KH, Golka K, Thier R, et al. (2000). Glutathione transferase isozyme genotypes in patients with prostate and bladder carcinoma. Arch. Toxicol. 74: 521-526.

Vijayalakshmi K, Vettriselvi V, Krishnan M, Shroff S, et al. (2005). Polymorphisms at GSTM1 and GSTP1 gene loci and risk of prostate cancer in a South Indian population. Asian Pac. J. Cancer Prev. 6: 309-314.

Wadelius M, Autrup JL, Stubbins MJ, Andersson SO, et al. (1999). Polymorphisms in NAT2, CYP2D6, CYP2C19 and GSTP1 and their association with prostate cancer. Pharmacogenetics 9: 333-340.

Waris G and Ahsan H (2006). Reactive oxygen species: role in the development of cancer and various chronic conditions. J. Carcinog. 5: 14.

Zimniak P, Nanduri B, Pikula S, Bandorowicz-Pikula J, et al. (1994). Naturally occurring human glutathione S-transferase GSTP1-1 isoforms with isoleucine and valine in position 104 differ in enzymic properties. Eur. J. Biochem. 224: 893-899. 